\title{
Thoracopagus: a first case of incomplete conjoint twins in Eritrea
}

\section{Dr. Zemichael Ogbe MD, Paediatrician'}

Institutional Affiliation:

'Orotta Paediatric Hospital, Department of Neonatology, Asmara, Eritrea

\section{Abstract}

An eight hour old boy with incomplete duplication of the head was admitted in a tertiary paediatric referral hospital in Asmara, the capital city of Eritrea. The incompletely developed head with the neck of one twin was attached to the much larger and more fully developed one on the anterior aspect (ventral) of the chest. This abnormal union or fixation is termed thoracopagus which is the second most common distribution of ventral unions, parapagus (pelvis and variable trunk) being the most common. Although thoracopagus twins are more frequent, omphalopagus twins are more commonly encountered at birth, due to lower fetal mortality.

The neonate also presented with multiple abnormalities, omphalocele, and congenital heart disease with VSD, deformed left external ear, high arched palate and supernumerary digit on the left $5^{\text {th }}$ finger of the hand.

\section{Introduction}

Generally conjoined twins are of great concern in resource poor countries in terms of investigations and management costs. Asymmetrical conjoined twins are the most striking anomaly of monozygotic twins which occurs when monozygotic twins fail to separate into two individuals and one of them fail to develop into a full complete individual and remains as a parasite attached to a well-developed individual ${ }^{1-3}$. One small and incompletely developed component, the "parasite", is joined to a fully developed one.

\section{Case Report}

The baby with $2.2 \mathrm{~kg}$ birth weight was a product of an uncomplicated pregnancy and home delivery. The duplicated and incompletely developed head was fixed on the anterior aspect of the chest of the fully developed twin (Thorachopagus). (Figures 1, 2)

On arrival at the hospital, the fully developed twin boy was in no apparent distress but was notable with big swelling mass on the umbilical cord area (omphalocele), facial asymmetry with deformed left external ear, high arched palate and a supernumerary digit on $5^{\text {th }}$ finger of the left hand. He also had a pansystolic murmur on LLSB that correlates with VSD as confirmed by echocardiogram. While the parasite, the head with its neck of the incompletely developed twin had no eyes, ears and nose but the scalp was covered with fairly well developed hair. The mouth was wide with relatively large tongue had primitive sucking reflex with excessive secretion that may suggest the presence of salivary glands. The head moved sideways and the posterior part of the neck was hard on palpation and was joined to the chest of the fully developed one by soft tissues and a bone that did not resemble the cervical vertebrae structure. The right side of the neck was longer than the left and no pulsation was felt on the lateral sides of the neck which suggested the absence of large arteries connecting the head with the fully developed twin.
Figure 1: The patient with the duplicated head attached on the chest

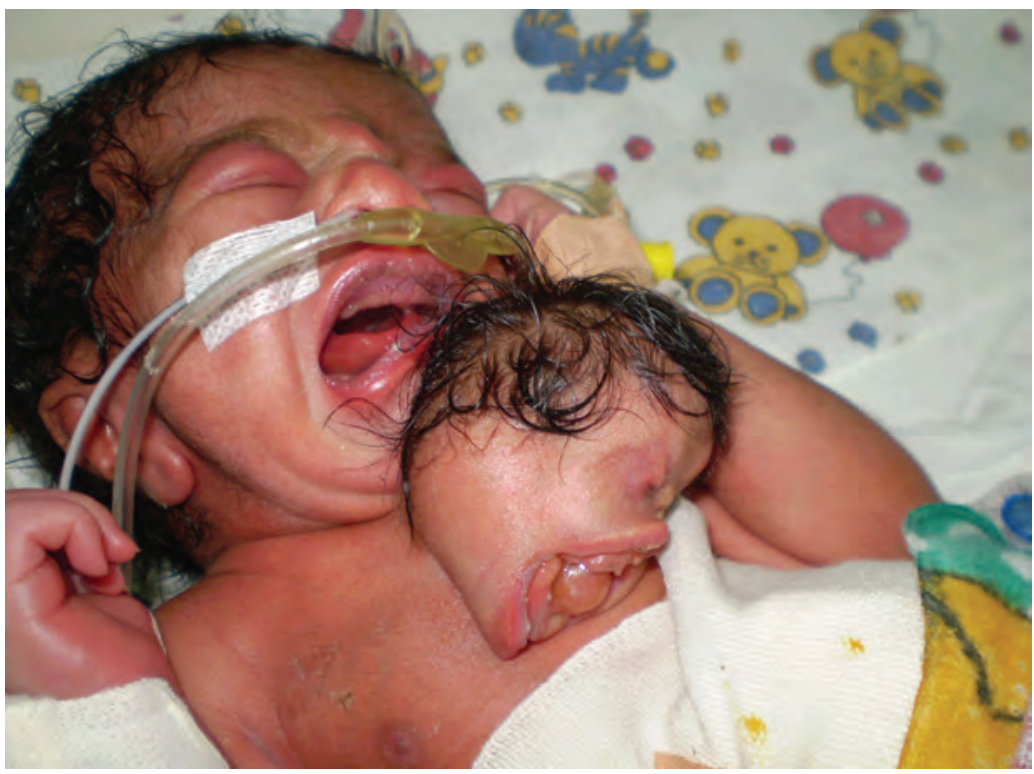

Figure 2: Same patient from a different angle

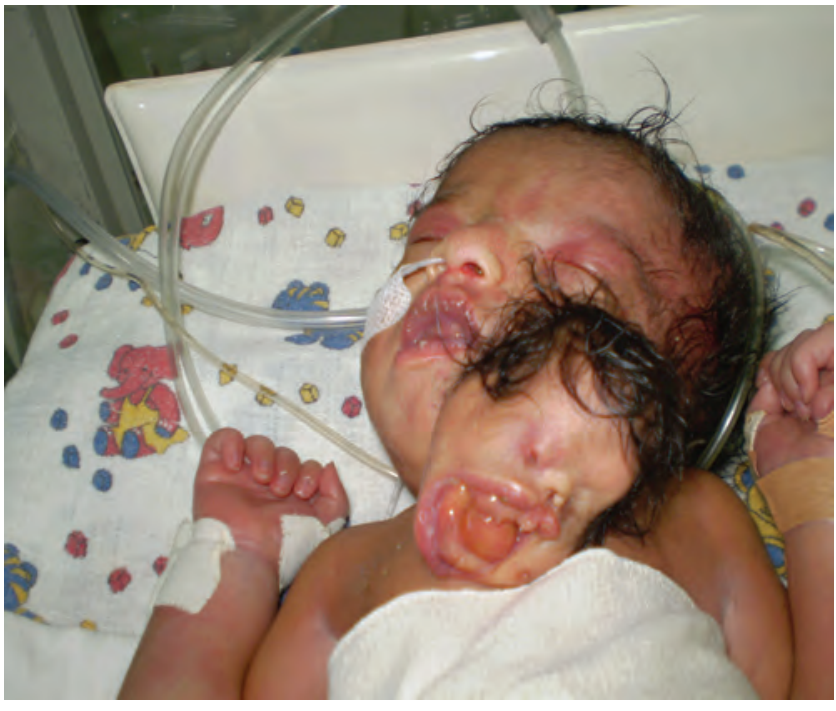

The baby was delivered by spontaneous vaginal delivery at home in a village near Dbarwa, a town 28 kilometers south from Asmara, the capital city of 
Eritrea, and was a product of a term gestation born to a 22- year old mother Gravida IV, Para III and Abortion1.

There was a history of normal twin delivery from the maternal side of the mother. No history of congenital malformations from the family of the mother or the father was reported.

The vital signs on admission were within normal range: Temperature, 36.60C; Pulse rate, 146 /Min; Respiratory rate, 42 per min; Oxygen saturation, 92\%; and Random blood sugar, $76 \mathrm{mg} / \mathrm{dl}$. Lateral X-ray revealed a piece of elongated bone, nothing to do with the structure of cervical vertebrae that connected the parasite's head to the chest. On the $5^{\text {th }}$ day of admission a decision was made to excise the parasite head.

The ethical considerations in this case tested the limits of all concerned, especially of the parents, who were often emotionally distraught and unable at first to make the kind of decisions that were often necessary. After substantial psychosocial support the mother finally agreed for operation.

Under general anaesthesia the head was removed with the findings of a piece of bone connected to the sternum of the well developed twin and two small seize blood vessels (a vein and an artery) (Figure 3).

Figure 3: The removed parasite head

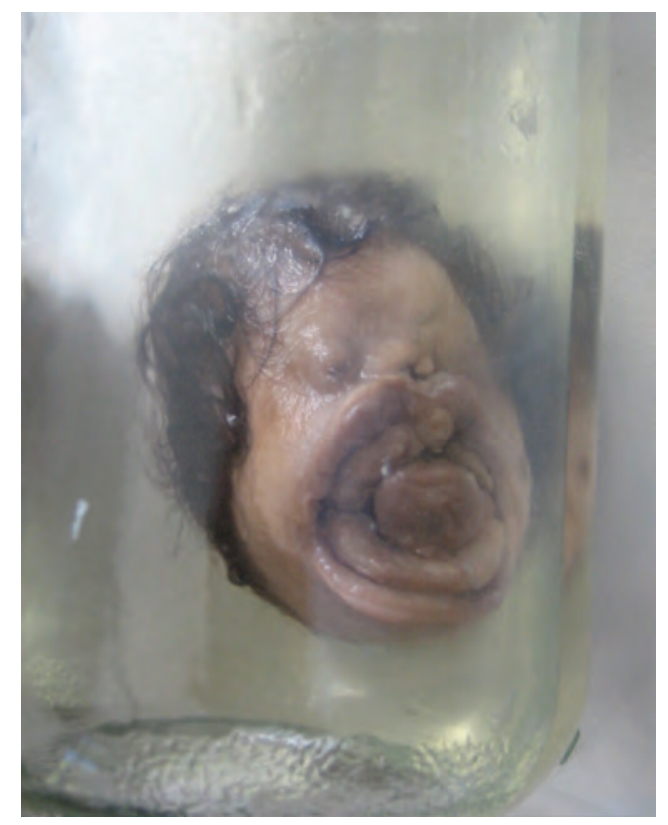

There was no major post operative complication and the baby was doing fine.

While the NICU was discussing with the surgeons and preparing for the second operation to correct the omphalocele the mother took the baby and disappeared without the consent of the hospital.

\section{Discussion}

Conjoined twins have been a source of fascination for both general public and medical profession since time immemorial. Their birth was initially viewed as an ominous sign of impending disaster. This was followed, in western by prolonged periods through the Middle Ages and into the nineteenth century when they were regarded as freaks or monstrosities and were exhibited with substantial financial reward at circuses and sideshows. Recently, conjoined twins have attracted intense media interest, which coincided with increasing success in their separation. The over all prognosis depends on the degree of organ sharing between fetuses.

Generally the incidence of conjoined twins ranges from 1 in 50,000 to 1 in 100,000 live births and the ratio of females to males is $3: 1^{4}$. The prevalence of symmetrical conjoined twins is higher than those asymmetrical twins or incomplete conjoined twins. In a study conducted in Hungary 1970-1986, for example, symmetrical conjoined twins had predominance of 92.3\% over the asymmetrical ${ }^{4}$.

Various degrees of fetal fusion result from incomplete division of the inner cell mass 13-15 days after fertilization. Although the precise causes are unknown, many authors believe that the factors responsible for monozygosity may play a role in conjoined twins ${ }^{2}$.

Conjoined twins can cause dystocia with the risk of rupture of the uterus, and quite often require cesarean section which may have negative consequences for the obstetrical future of the mother. However, an early ultrasound diagnostic can modify prognosis and allow medical termination of pregnancy in case of seriously malformed thoracopagus conjoined twins. The risk that the condition recurs in a subsequent pregnancy may be considered negligible? .

Traditionally incomplete twinning was explained by duplications of not only external structure but also by internal organs. But there has recently been suggested in possible human homologues of the mouse mutant disorganization as a primary cause of incomplete twinning. This mutant gene "disrupts the orderly process of organogenesis and induces a great variety of developmental anomalies in structures derived from all germ layers" ${ }^{\prime \prime}$. It is inherited in a semidominant manner.

The deformed left ear and high arched palate in this particular patient are compatible with the multiple cranial abnormalities seen in disorganization. However, the cardiac findings and the abdominal defect does not match with birth defect seen in disorganization.

Certainly, "Incomplete twining" does not seem to be able to account for the range of abnormalities seen in this particular patient.

\section{Reference:}

1 Spencer R. Anatomic description of conjoined twins; a plea for standardized terminology. J Peditr Surg1996;31(7): 941-4.

2. Grutter $F$, et al. Thoracopagus fetos.Ultrasonic diagnosis at 16weeks, J Gynecol Obstet Biol Repord.1989; 18(3):355-9.

3 Spitz L; Kiely EM. Conjoined twins, Jama 2003 Mar 12;289(10);1370-10.

4 Metneki J; Czeizil A. Conjoined twins in Hungary, 1970-1986. Acta Genet Med Gemellol. 1989; 38(3-4): 285-99.

5 Petzel M.A ; Erickson R.P Disorganisation: a possible cause of apparent conjoint twinning, J Med Genet1991;28: 712-714 